\title{
A cross-sectional study of intestinal parasitoses in dogs and children of the periurban area of La Plata (Buenos Aires, Argentina): Zoonotic importance and implications in public health
}

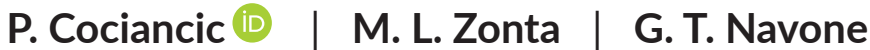

Centro de Estudios Parasitológicos y de Vectores (CEPAVE-CONICET-UNLP), La Plata, Buenos Aires, Argentina

\section{Correspondence}

Paola Cociancic, Centro de Estudios Parasitológicos y de Vectores (CEPAVECONICET-UNLP), La Plata, Buenos Aires, Argentina.

Email: paolacociancic@cepave.edu.ar

Funding information

UNLP, Grant/Award Number: N759; PIP CONICET, Grant/Award Number: N734; PIO CONICET-UNLP, Grant/Award Number: N13420130100004CO

\section{Summary}

A cross-sectional study was performed between school term dates 2014 and 2015 to diagnose intestinal parasites in dogs and children living with them. The socioenvironmental characteristics and hygiene practices of the children were also evaluated in terms of risk factors for parasitic infection of periurban neighbourhoods of La Plata (Buenos Aires, Argentina). Serial coproparasitological samples of 78 dogs and 211 children were analysed by means of concentration and flotation techniques. Socio-environmental variables and hygiene practices of children were evaluated through semi-structured questionnaires which were answered by every family. The study showed that $82.1 \%$ of dogs were parasitized. The specific richness was of 11 species; Ancylostoma caninum (69.2\%), Uncinaria stenocephala (41.0\%), Trichuris vulpis (28.2\%) and Toxocara canis (21.8\%) were the most prevalent. The study also revealed that $67.8 \%$ of children were positive. Also, 11 species were identified and the most prevalent were Blastocystis sp. (36.0\%), Enterobius vermicularis (27.5\%) and Giardia lamblia (21.3\%). The risk for parasitosis was higher in 6-year-old children and older (OR $=1.9$, 95\% IC: $1.0-3.7)$ and in those who did not wash their hands or did it occasionally after playing with their pets (OR $=2.8,95 \% \mathrm{IC}: 1.4-5.5)$. Blastocystis sp. and Entamoeba coli infection risks were greater in children whose parents had a basic level of education (OR = 3.4, 95\% IC: $1.3-8.7$ and OR = 3.6, 95\% IC: 0.8-15.9, respectively). In addition, the risk of infection for $E$. coli was higher in children who lived in floodable houses (OR $=4.4,95 \%$ IC: $0.9-16.6$ ). Likewise, the risk of infection for E. vermicularis was greater in children with onychophagia (OR = 1.6, 95\% IC: 0.7-3.7) and in 6 year olds and older whose parents completed only primary studies (OR = 3.6, 95\% IC: 1.4 9.1). The results obtained show the existence of a worrying epidemiological scenario that stresses the importance of zoonotic parasitosis as a serious problem of public health.

\section{KEYWORDS}

Argentina, children, dogs, intestinal parasites, risk factors, zoonosis 


\section{1 | INTRODUCTION}

Dogs (Canis familiaris) play very important roles as hosts and reservoirs of numerous intestinal parasites, and the mechanisms of infection vary according to the parasitic species (e.g. Toxocara canis, Ancylostoma caninum, Uncinaria stenocephala) (Traversa, 2012; Zanzani, Gazzonis, Scarpa, Berrilli, \& Manfredi, 2014). For example, by direct or indirect contact with the secretions or depositions of infected dogs and by ingestion of an intermediary host, among others (Bwalya, Nalubamba, Hankanga, \& Namangala, 2011; Gamboa et al., 2009; Traversa et al., 2011; Traversa et al., 2014). In this respect, some of these parasitoses are potentially zoonotic and can affect human health, especially that of children due to the close relationship they develop with their pets and also due to insufficient hygiene practices, inadequate disposition of canine faeces and lack of environmental sanitation (Amissah-Reynolds, Monney, Adowah, \& Agyemang, 2016; Dantas-Torres \& Otranto, 2014; Soriano et al., 2010). The impact of these infections in human beings is relatively high in developing countries where sanitary conditions are inadequate and the access to education and health is unequal (Dantas-Torres \& Otranto, 2014). In this context, Argentina is one of the most urbanized Latin American countries whose population has grown since 2001 towards periurban and rural areas lacking in planification and governmental intervention and, thus, causing new socio-environmental problems (Oyhenart et al., 2013). This situation is particularly evident in the periurban area of La Plata, province of Buenos Aires, where the environmental heterogeneity and the different cultural and social patterns determine variations at a sanitary-epidemiological level (Gamboa, Giambelluca, \& Navone, 2014). In this sense, parasitic infections of human and animal populations represent a serious public health problem.

Several studies have shown heterogeneity in the prevalence of enteroparasitosis in dogs and children in Argentina due to the complex mosaic of climatic and socioeconomic variability of the country (Dopchiz et al., 2013; La Sala, Leiboff, Burgos, \& Costamagna, 2015; Navone et al., 2017; Semenas et al., 2014; Socías, Fernández, Gil, \& Krolewiecki, 2014; Soriano et al., 2010). However, only a few approached the problem of parasitic zoonosis in relation to human parasitosis and socio-environmental characteristics of the population.

Our study is based on the hypothesis that the deficient socioenvironmental situation and the inadequate hygiene practices to which children are exposed, increase the risk for parasitic infection. Considering this, two objectives were proposed as follows: (i) to diagnose intestinal parasites in dogs and in children living with them of the periurban neighbourhoods of La Plata (Buenos Aires, Argentina), and (ii) to evaluate the socio-environmental characteristics and hygiene practices of children as risk factors of parasitic infection. This study focuses on the "One Health" approach considering the health of people and that of animals and the environment from a holistic point of view.

\section{Impacts}

- More than $80.0 \%$ of dogs were parasitized with pathogenic species. These species are of zoonotic importance and can affect human health, especially that of children.

- $67.8 \%$ of children were parasitized and the species found indicate insufficient hygiene practices and deficient socio-environmental characteristics. The risk factors for parasitic infection were no handwashing after playing with pets, onychophagia, flooding and a basic level of education of parents.

- This worrying epidemiological scenario suggests the need to implement activities of prevention, surveillance and control of intestinal parasites in an integrated approach.

\section{2 | MATERIALS AND METHODS}

\subsection{Study area}

The area of study included periurban neighbourhoods of La Plata $\left(34^{\circ} 55^{\prime} \mathrm{S}, 57^{\circ} 57^{\prime} \mathrm{W}\right)$, North-East of the province of Buenos Aires (Argentina; Figure 1). La Plata is located near the Río de La Plata and $60 \mathrm{~km}$ away from the Autonomous City of Buenos Aires. It has a total surface area of $926 \mathrm{~km}^{2}$ and a population of approximately 654,000 inhabitants (INDEC, 2010). It has an average annual temperature of $17^{\circ} \mathrm{C}$ and a relative humidity of $78 \%$. Annual rainfall is about $1,000 \mathrm{~mm}$, and its soil is abundant in organic waste, and it has a silt-loam texture (Hurtado, Giménez, \& Cabral, 2006). Eight periurban neighbourhoods (Abasto, El Carmen, El Peligro, Los Hornos, Melchor Romero, Ringuelet, San Carlos and Tolosa) were randomly selected among those affected by the major flood of April 2013, which aggravated pre-existing sanitary problems such as precarious housing with limited access to public services. Only $35 \%-55 \%$ of the periurban area is connected to the local sewage system and has drinking water (Gamboa et al., 2014; Oyhenart et al., 2013). Most families attend Primary Health Care Centers (CAPS, for its acronym in Spanish) for essential health care. When more specialized health care is required, they are derived to public hospitals in the urban area. With respect to health care for pets, some services are offered for free occasionally in some neighbourhoods, such as castrations and vaccinations.

\section{2 | Samples collection}

A cross-sectional study was performed between school term dates 2014 and 2015 in different periurban neighbourhoods of La Plata. This study started with meetings for adults and children in different institutions (e.g. public primary schools, CAPS, non-governmental organizations) in order to inform the population about the biology of intestinal parasites, their means of transmission and strategies to prevent intestinal parasitoses. Then, parasitological tests were offered for free for dogs and children belonging to the participating families. 
FIGURE 1 Geographic location of Argentina in South America and Buenos Aires province in Argentina (a), District of La Plata (b) and analysed periurban neighbourhoods (c) LP, La Plata; 1, San Carlos; 2, Melchor Romero; 3, Los Hornos; 4, Abasto; 5, El Peligro; 6, Ringuelet; 7 . Tolosa; 8, El Carmen
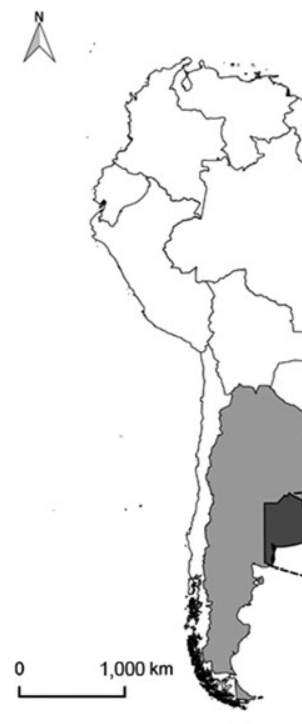

(a)

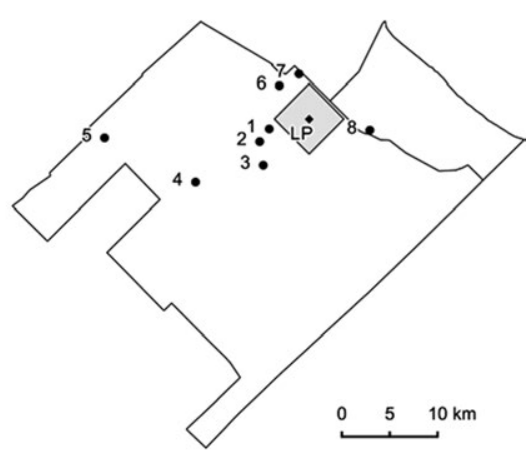

(c)
Every consenting family was provided with one vial for each dog and two vials for each child containing $10 \% \mathrm{v} / \mathrm{v}$ of aqueous formaldehyde for stool samples and anal swabs to diagnose intestinal parasites.

Faeces from dogs $(n=78)$ were collected during 5-7 days by their owners or by the research team immediately after deposition, or by a veterinarian when taken from the animal's rectum. Children's faecal and anal swabs samples $(n=211)$ were collected by their parents or legal guardians prior verbal and written instructions during 5-7 days. Anal swabs were obtained from the perianal zone during the morning using sterile gauze.

The sample selection was non-probabilistic and was largely determined by voluntary participation. The study included children of both sexes under the age of 15 years, whose parents or legal guardians had given written consent. Also, dogs of the participating families took part of the study. Sex and age of dogs were not considered. Those who had received antiparasitic treatment by the time of the research were excluded.

\subsection{Ethical aspects}

The study was carried out without affecting the physical, psychic and moral integrity of the participants and securing their identity. The present work was evaluated and approved by the Comité de Ética de la Escuela Latinoamericana de Bioética (CELABE) under Resolution No. 003/2016, Record No. 73. The study was conducted attending the principles proclaimed in the Universal Declaration of Human Rights (1948), the ethical standards established by the Nüremberg Code (1947), the Declaration of Helsinki (1964) and its successive amendments. Special attention was also paid to Article 5 of the Regulation Decree of National Law 25.326.

\section{4 | Parasitological analysis}

In the laboratory of Biodiversity and Parasitic Epidemiology of the Centro de Estudios Parasitológicos y de Vectores (La Plata, Buenos Aires, Argentina), the coproparasitological samples were processed using the techniques of concentration by sedimentation (Ritchie) and flotation (Willis). The anal-swab vials were agitated vigorously and centrifuged for $10 \mathrm{~min}$ at $400 \mathrm{~g}$ to obtain a pellet with the highest possible concentration of eggs of Enterobius vermicularis (Becerril Flores \& Romero Cabello, 2004; WHO, 1991). Temporary staining (lugol) was used when necessary. Every sample was examined by two experts using an optical microscope to $100 \times$ and $400 \times$ magnifications. Identification of eggs, cysts and larvae was based on their measures and morphological characteristics (Mehlhorn, Düwel, \& Raether, 1992; Thienpont, Rochette, \& Vanparijs, 1979; WHO, 1994).

\section{5 | Socio-environmental data collection}

A semi-structured questionnaire was completed by each parent or legal guardian ( $n=205)$, who answered voluntarily about the characteristics of the houses and families. The questionnaire was designed by the research group advised by other professionals in the area. During the meetings, the questionnaire was distributed among the participants and, only when necessary, the research group helped respondents. The questionnaire aimed at gathering information about house building material, lodging or house tenure status, flooring, road condition, source of drinking water, wastewater disposal, solid waste disposal, flooding, overcrowding (more than three people per room), pet ownership, health insurance, parents' education level, parents' employment, governmental food and monetary support, animal husbandry and orchard for own consumption. As for hygiene practices, the questionnaire included questions about hand washing before eating and after going to the toilet and caressing pets, washing of raw vegetables and fruits, walking barefoot, onychophagia and playing in the soil.

\section{6 | Statistical analysis}

A sample was considered positive when at least a parasitic species was observed by any diagnostic method. The general prevalence 
(the number of parasitized hosts divided by the total number of analysed hosts, expressed in terms of percentage) was calculated, and also the relative prevalence (the number of parasitized hosts by a given species divided by the total number of parasitized hosts, expressed in terms of percentage), the specific richness (the number of parasitic species) and the percentage of monoparasitized, biparasitized and polyparasitized hosts (three or more parasitic species per host). Parasitological results and socio-environmental data were entered into a unique database and imported into the software $R(R$ Core Team, 2015). The parasitoses and parasitic species detected were analysed statistically (independent variables, all binomials) in relation to the demographic information (sex and age), the socioenvironmental characteristics and hygiene practices (dependent and categorical variables). The association between pairs of species was examined as well. The independence of variables was evaluated using the Chi-square test $\left(\chi^{2}\right)$ and, when the expected values were lower than 5, Fisher's exact test was performed. Likewise, the variables that turned out to be significantly associated with the parasitoses $(p<.05)$ were evaluated by means of logistic regression models using stepwise forward variables selection to determinate risk factors for parasitic infection in children. The model with the lowest residual deviance (RD) was chosen and, in the case of several competitive models, the most parsimonious was used comparing Akaike information criterion (AIC) and $p$ value. Association force was estimated by odds ratio (OR) values.

Children were divided into two groups according to their school age: 5-year-old children and younger and 6-year-old children and older. To perform a regression analysis, parents' education level was grouped in primary (basic level) and in secondary/tertiary/university (superior level).

\section{3 | RESULTS}

\section{1 | Parasitological analysis in dogs}

Of the total number of analysed dogs, $82.1 \%$ was parasitized with at least one species. The specific richness was of 11 species. All species were pathogenic, and the most prevalent was A. caninum (69.2\%), followed by U. stenocephala (41.0\%), T. vulpis (28.2\%) and T. canis (21.8\%) and others of lower prevalence (Table 1). Moreover, eggs of Ascaris spp. (2.6\%) and of T. trichiura (1.3\%) were found. The general and relative prevalence of parasitic species is shown in Table 1.

Polyparasitism (39.1\%) was higher with respect to the infections with one $(32.8 \%)$ or two (28.1\%) species. Monoparasitism was mainly represented by A. caninum (18.0\%) and T. canis (6.4\%). Regarding biparasitism, the most common infections occurred between A. caninum/U. stenocephala (11.5\%) and A. caninum/T. vulpis (7.7\%). In the case of polyparasitism, the most frequent combinations were $A$. caninum/U. stenocephala/T. vulpis (6.4\%) and A. caninum/U. stenocephala/T. vulpis/T. canis (5.1\%) with a maximum of six species (A. caninum, U. stenocephala, T. vulpis, Entamoeba spp., Ascaris spp. and T. trichiura). A statistically significant association was observed between A. caninum and $U$. stenocephala $\left(\chi^{2}=13.4 ; p<.01\right)$ and A. caninum and T. vulpis $\left(\chi^{2}=8.3 ; p<.01\right)$.
TABLE 1 General and relative prevalence of parasitic species in dogs from periurban neighbourhoods of La Plata

\begin{tabular}{|c|c|c|c|}
\hline Parasitic species & $\begin{array}{l}\text { Number of } \\
\text { positive } \\
\text { samples }\end{array}$ & $\begin{array}{l}\text { General } \\
\text { prevalence } \\
(n=78)\end{array}$ & $\begin{array}{l}\text { Relative } \\
\text { preva- } \\
\text { lence }^{\text {b }} \\
(n=64)\end{array}$ \\
\hline \multicolumn{4}{|l|}{ Nematodes } \\
\hline Ancylostoma caninum & 54 & 69.2 & 84.4 \\
\hline Uncinaria stenocephala & 32 & 41.0 & 50.0 \\
\hline Trichuris vulpis & 22 & 28.2 & 34.4 \\
\hline Toxocara canis & 17 & 21.8 & 26.6 \\
\hline Eucoleus aerophilus & 1 & 1.3 & 1.6 \\
\hline Toxascaris leonina & 1 & 1.3 & 1.6 \\
\hline \multicolumn{4}{|l|}{ Cestodes } \\
\hline Dipylidium caninum & 1 & 1.3 & 1.6 \\
\hline \multicolumn{4}{|l|}{ Protozoa } \\
\hline Giardia lamblia & 8 & 10.3 & 12.5 \\
\hline Entamoeba spp. & 8 & 10.3 & 12.5 \\
\hline Total & 64 & 82.1 & 100 \\
\hline
\end{tabular}

${ }^{a}$ General prevalence was estimated in relation to the total number of analysed dogs $(n=78)$.

${ }^{\mathrm{b}}$ Relative prevalence was estimated in relation to the total number of positive dogs $(n=64)$.

\section{2 | Parasitological analysis in children}

Two hundred and eleven children of both sexes were analysed ( $54.0 \%$ boys and $46.0 \%$ girls) ages ranging 4 months to 15 years old (34.8\% preschoolers and $60.2 \%$ schoolchildren). Of the total number of analysed children, $67.8 \%$ was parasitized with at least one species. Infection by pathogenic species was higher than infection by non-pathogenic species (64.0\% versus $3.8 \%$, respectively). The specific richness was of 11 species, and the most prevalent were Blastocystis sp. (36.0\%), E. vermicularis (27.5\%) and G. Iamblia (21.3\%), followed by others of lower prevalence (Table 2). Boys resulted to be more parasitized than those of girls $(54.6 \%$ versus $45.4 \% ; p>.05$ ), as well as 6-year-old children and older were significantly more parasitized than younger children $(65.0 \%$ versus $\left.35.0 \% ; \chi^{2}=3.7 ; p<.05\right)$. The differences observed among the species found and the sex of children were not significant $(p>.05)$. However, regarding the age group, $E$. vermicularis was significantly more frequent in 6-year-old children and older $(77.6 \%$ versus $\left.22.4 \% ; \chi^{2}=9.1 ; p<.01\right)$.

The infection by one species (57.3\%) was higher in comparison with biparasitism (22.4\%) and poliparasitism (20.3\%). Statistically significant associations were observed between Entamoeba coli/Endolimax nana ( $p=.003)$, E. coli/G. lamblia $\left(\chi^{2}=5.4 ; p<.05\right)$, E. coli/Blastocystis sp. $\left(\chi^{2}=9.6 ; p<.01\right)$, E. coli/Hymenolepis nana $(p=.01)$ and E. coli/Ascaris lumbricoides $(p=.0002)$. Moreover, Blastocystis sp./H. nana $(p=.01)$ and T. trichiura/E. nana $(p=.02)$, T. trichiura/Enteromonas hominis $(p=.03)$ and T. trichiura/A. lumbricoides $(p=.006)$ were associated. 
TABLE 2 General and relative prevalence of parasitic species in children from periurban neighbourhoods of La Plata

\begin{tabular}{|c|c|c|c|}
\hline Parasitic species & $\begin{array}{l}\text { Number of } \\
\text { positive } \\
\text { samples }\end{array}$ & $\begin{array}{l}\text { General } \\
\text { prevalence }^{a} \\
(n=211)\end{array}$ & $\begin{array}{l}\text { Relative } \\
\text { preva- } \\
\text { lence }^{\text {b }} \\
(n=143)\end{array}$ \\
\hline \multicolumn{4}{|l|}{ Protozoa } \\
\hline Blastocystis sp. & 76 & 36.0 & 53.2 \\
\hline Giardia lamblia & 45 & 21.3 & 31.5 \\
\hline Entamoeba coli & 24 & 11.4 & 16.8 \\
\hline Endolimax nana & 20 & 9.5 & 14.0 \\
\hline Enteromonas hominis & 2 & 1.0 & 1.4 \\
\hline lodamoeba bütschlii & 1 & 0.5 & 0.7 \\
\hline \multicolumn{4}{|l|}{ Helminths } \\
\hline \multicolumn{4}{|l|}{ Geohelminths } \\
\hline $\begin{array}{l}\text { Ascaris } \\
\text { lumbricoides }\end{array}$ & 10 & 4.7 & 7.0 \\
\hline Trichuris trichiura & 3 & 1.4 & 2.1 \\
\hline $\begin{array}{l}\text { Strongyloides } \\
\text { stercoralis }\end{array}$ & 3 & 1.4 & 2.1 \\
\hline \multicolumn{4}{|l|}{ No geohelminths } \\
\hline $\begin{array}{l}\text { Enterobius } \\
\text { vermicularis }\end{array}$ & 58 & 27.5 & 40.6 \\
\hline Hymenolepis nana & 9 & 4.3 & 6.3 \\
\hline Total & 143 & 67.8 & 100.0 \\
\hline Pathogenic species & 135 & 64.0 & 94.4 \\
\hline $\begin{array}{l}\text { Non-pathogenic } \\
\text { species }\end{array}$ & 8 & 3.8 & 5.6 \\
\hline
\end{tabular}

${ }^{a}$ General prevalence was estimated in relation to the total number of analysed children $(n=211)$.

${ }^{b}$ Relative prevalence was estimated in relation to the total number of positive children ( $n=143$ ).

\section{3 | Socio-environmental analysis}

The results obtained from the questionnaires are shown in Table 3. Most families owned the houses, which were made with fired brick masonry or pre-fabricated, and in minor proportion, with makeshift materials (sheet, wood, nylon or cardboard). The majority of the houses were not connected to the local sewage system and used septic tank and latrines for wastewater disposal. They were generally supplied with piped water system and provided with public waste collection services. Roads were mostly of dirt and the houses flooded frequently. A $67.3 \%$ of families lived under critical crowding conditions. As regards the education of parents, the majority of them had only a basic level of education (primary education). Approximately $51.2 \%$ of fathers were employed (formal jobs) or had freelance jobs (autonomous), and the rest were unemployed or had temporary jobs. Mothers were mostly unemployed or housewives, and the rest claimed they had formal or temporary jobs. Approximately $56.1 \%$ of families received governmental monetary support; $26.3 \%$ of children received governmental food support, and only $13.7 \%$ had health insurance. Finally, $87.8 \%$ of families owned pets and just a few practised animal husbandry and orchard agriculture for personal consumption (Table 3).

As for hygiene practices, most adults stated that their children always washed their hands before eating (64.4\%) and after going to the toilet (58.0\%). However, the majority did not usually do so after playing with or caressing their pets. In addition, most children usually walked barefoot or always did, had onychophagia and played in the soil. Most of the adults said they washed fruits and raw vegetables (76.1\%) (Table 4).

\subsection{Infection risk factors in children}

Table 5 shows the variables selected by the Chi-square test and Fisher's exact test, which have revealed significant differences of parasitosis and infection for Blastocystis sp., E. vermicularis and E. coli. These variables were included in logistic regression models, and the results are shown in Table 6. In this respect, it was observed that the risk for parasitosis was greater in 6-year-old children and older (OR $=1.9,95 \%$ IC: $1.0-3.7)$ and in those who did not wash their hands or did it occasionally after playing with their pets $(\mathrm{OR}=2.8,95 \% \mathrm{IC}$ : 1.4-5.5).

The analysis of each parasitic species showed that the risk of infection for Blastocystis sp. was higher in children whose parents only had primary studies (OR $=3.4,95 \%$ IC: $1.3-8.7)$. The model also showed that children whose mothers had no studies or whose education level was basic were more likely to be infected by E. coli (OR $=3.6$, 95\% IC: 0.8-15.9), as well as children whose houses flooded frequently (OR $=4.4,95 \%$ IC: $0.9-16.6)$. On the other hand, the risk of infection for E. vermicularis was greater in children with onychophagia (OR $=1.6,95 \% \mathrm{IC}: 0.7-3.7)$ and in 6 year olds and older whose parents completed only primary studies (OR $=3.6,95 \%$ IC: 1.4-9.1).

\section{4 | DISCUSSION}

This study provides parasitological and socio-environmental data related to dogs and children from the periurban neighbourhoods of La Plata (Buenos Aires, Argentina) that suggest a worrying epidemiological scenario for public health. Intestinal parasites in dogs and children living with them were diagnosed. Socio-environmental characteristics and hygiene practices were assessed as well to evaluate possible risk factors in children.

Several studies were carried out to determine the prevalence of intestinal parasites in dogs in other countries, with different results (Amissah-Reynolds et al., 2016; Zanzani et al., 2014). In Argentina, heterogeneous values of prevalence in dogs were reported by different authors (36.6\%-69.8\%) (Dopchiz et al., 2013; La Sala et al., 2015; Soriano et al., 2010). In this study, high prevalence of enteroparasitosis in dogs (82.1\%) gave account of great canine faecal contamination and deficient health care of pets, which can affect both animal and human sanitation. 
TABLE 3 Socio-environmental characteristics of the population from the periurban neighbourhoods of La Plata

\begin{tabular}{|c|c|c|}
\hline \multirow[b]{2}{*}{ Characteristics } & \multicolumn{2}{|c|}{ Frequency $^{a}$} \\
\hline & No. & $\%$ \\
\hline \multicolumn{3}{|l|}{ Lodging or house tenure status } \\
\hline House owner & 154 & 75.1 \\
\hline Lease holder & 20 & 9.8 \\
\hline Free lodging & 23 & 11.2 \\
\hline Non-answered & 8 & 3.9 \\
\hline \multicolumn{3}{|l|}{ Building materials } \\
\hline Fired-brick masonry or prefabricated & 136 & 66.3 \\
\hline Makeshift material & 68 & 33.2 \\
\hline Non-answered & 1 & 0.5 \\
\hline \multicolumn{3}{|l|}{ Flooring } \\
\hline Concrete or other & 179 & 87.3 \\
\hline Dirt & 25 & 12.2 \\
\hline Non-answered & 1 & 0.5 \\
\hline \multicolumn{3}{|l|}{ Wastewater disposal } \\
\hline Septic tank & 82 & 40.0 \\
\hline Latrine & 77 & 37.6 \\
\hline Open-air defecation & 18 & 8.8 \\
\hline Sewage system & 27 & 13.2 \\
\hline Non-answered & 1 & 0.5 \\
\hline \multicolumn{3}{|l|}{ Drinking water (main source) } \\
\hline Piped water system & 170 & 82.9 \\
\hline Protected well & 23 & 11.2 \\
\hline Public tap & 12 & 5.9 \\
\hline \multicolumn{3}{|l|}{ Solid waste disposal } \\
\hline Open-air pits, incineration or non-sanitary burial & 43 & 21.0 \\
\hline Public waste collection & 162 & 79.0 \\
\hline \multicolumn{3}{|l|}{ Flooding } \\
\hline Never & 61 & 29.8 \\
\hline Occasionally & 115 & 56.1 \\
\hline Always & 22 & 10.7 \\
\hline Non-answered & 7 & 3.4 \\
\hline \multicolumn{3}{|l|}{ Roads condition } \\
\hline Paved & 85 & 41.5 \\
\hline Dirt & 120 & 58.5 \\
\hline \multicolumn{3}{|l|}{ Critical crowding } \\
\hline Yes & 138 & 67.3 \\
\hline No & 57 & 27.8 \\
\hline Non-answered & 10 & 4.9 \\
\hline \multicolumn{3}{|l|}{ Mother's education } \\
\hline Unschooled & 8 & 3.9 \\
\hline Primary & 139 & 67.8 \\
\hline Secondary & 45 & 21.9 \\
\hline Tertiary/University & 4 & 2.0 \\
\hline Non-answered & 9 & 4.4 \\
\hline
\end{tabular}

(Continues)
TABLE 3 (Continued)

\begin{tabular}{|lrr|} 
& \multicolumn{2}{c}{ Frequency $^{\mathrm{a}}$} \\
\cline { 2 - 3 } & No. & \multicolumn{1}{c}{$\%$} \\
\hline Characteristics & & \\
\hline Father's education & 132 & 64.4 \\
\hline Primary & 32 & 15.6 \\
\hline Secondary & 3 & 1.5 \\
\hline Tertiary/University & 38 & 18.5 \\
\hline Non-answered & & \\
\hline Mother's employment & 138 & 67.3 \\
\hline Unemployed/Housewife & 19 & 9.3 \\
\hline Temporary & 41 & 20.0 \\
\hline Employed/Freelance & 7 & 3.4 \\
\hline Non-answered & & \\
\hline Father's employment & 6 & 2.9 \\
\hline Unemployed & 68 & 33.2 \\
\hline Temporary & 105 & 51.2 \\
\hline Employed/Freelance & 26 & 12.7 \\
\hline Non-answered & 115 & 56.1 \\
\hline Monetary support & 54 & 26.3 \\
\hline Food support & 20 & 9.8 \\
\hline Animal husbandry & 16 & 7.8 \\
\hline Orchard & 28 & 13.7 \\
\hline Health insurance & 87.8 \\
\hline Pet ownership & & \\
\hline & & \\
\hline
\end{tabular}

${ }^{\mathrm{a}}$ Frequency was estimated in relation to the total number of children with socio-environmental data $(n=205)$.

This research showed a large specific richness (11 species), which was within the range of 6-12 species documented in dogs worldwide (Fontanarrosa, Vezzani, Basabe, \& Eiras, 2006; Semenas et al., 2014; Zanzani et al., 2014). The most prevalent species were A. caninum, U. stenocephala, T. vulpis and T. canis. Other studies indicated similar results regarding the presence of these parasites in other countries (Bwalya et al., 2011; Letra Mateus, Castro, Ribeiro, \& Vieira-Pinto, 2014) and in other localities of Argentina (La Sala et al., 2015; Semenas et al., 2014). It is important to note that these parasite species previously mentioned are widely known as potential agents of zoonosis. The zoonotic importance of $A$. caninum resides in that its larvae survive in the environment for several months being able to penetrate the human epidermis by direct contact and cause the cutaneous larva migrans syndrome. This disease has also been associated to U. stenocephala, the second most prevalent species found in our research (Bowman, Montgomery, Zajac, Eberhard, \& Kazacos, 2010; Feldmeier \& Schuster, 2012). With respect to T. vulpis, its eggs can survive for years in the soil and people can accidentally ingest them due to their close contact with dogs or contaminated soil. Reported cases of infection have been asymptomatic and some were associated with the visceral larva migrans syndrome (Dunn, Columbus, Aldeen, Davis, \& Carroll, 2002; Traversa et al., 2011). Toxocara canis is one of 
TABLE 4 Hygiene practices of the population from the periurban neighbourhoods of La Plata

\begin{tabular}{|c|c|c|}
\hline \multirow[b]{2}{*}{ Hygiene practices } & \multicolumn{2}{|c|}{ Frequency ${ }^{a}$} \\
\hline & No. & $\%$ \\
\hline \multicolumn{3}{|c|}{ Handwashing before eating } \\
\hline Never & 2 & 1.0 \\
\hline Occasionally & 39 & 19.0 \\
\hline Always & 132 & 64.4 \\
\hline Non-answered & 32 & 15.6 \\
\hline \multicolumn{3}{|c|}{ Handwashing after going to the toilet } \\
\hline Never & 5 & 2.4 \\
\hline Occasionally & 51 & 24.9 \\
\hline Always & 119 & 58.0 \\
\hline Non-answered & 30 & 14.6 \\
\hline \multicolumn{3}{|c|}{ Handwashing after playing with pets } \\
\hline Never & 11 & 5.4 \\
\hline Occasionally & 87 & 42.4 \\
\hline Always & 74 & 36.1 \\
\hline Non-answered & 33 & 16.1 \\
\hline \multicolumn{3}{|l|}{ Walked barefoot } \\
\hline Never & 63 & 30.7 \\
\hline Occasionally & 83 & 40.5 \\
\hline Always & 31 & 15.1 \\
\hline Non-answered & 28 & 13.7 \\
\hline \multicolumn{3}{|l|}{ Onychophagia } \\
\hline Never & 65 & 31.7 \\
\hline Occasionally & 56 & 27.3 \\
\hline Always & 56 & 27.3 \\
\hline Non-answered & 28 & 13.7 \\
\hline \multicolumn{3}{|l|}{ Playing in the soil } \\
\hline Never & 34 & 16.6 \\
\hline Occasionally & 104 & 50.7 \\
\hline Always & 48 & 23.4 \\
\hline Non-answered & 19 & 9.3 \\
\hline \multicolumn{3}{|c|}{ Washing of fruits and vegetables } \\
\hline Never & 0 & 0.0 \\
\hline Occasionally & 23 & 11.2 \\
\hline Always & 156 & 76.1 \\
\hline Non-answered & 26 & 12.7 \\
\hline
\end{tabular}

${ }^{a}$ Frequency was estimated in relation to the total number of children with socio-environmental data $(n=205)$.

the most common parasites in canines, and it can be transmitted to human beings by the ingestion of embryonated eggs through the soil and contaminated hands or vegetables, or by the ingestion of larvae in undercooked meat of paratenic hosts (e.g. chickens, pigs, ruminants) (Overgaauw \& van Knapen, 2013). This parasite can cause visceral, pulmonary, ocular, neural larva migrans syndrome and symptoms vary depending on the organ affected and the degree of infection (Lee,
Schantz, Kazacos, Montgomery, \& Bowman, 2010). This species affects mostly children because of their close contact with pets and due to insufficient hygiene practices, which was accounted for in this study (the majority of children did not usually wash their hands after playing with their pets, walked barefoot and played in the soil).

The less prevalent species in this research were D. caninum, E. aerophilus, T. leonina and G. lamblia. In spite of this, these species represent a threat for human health and should therefore not be underestimated, especially for children who share playgrounds with pets (Dado et al., 2012; Letra Mateus et al., 2014; Traversa et al., 2011; Zanzani et al., 2014).

Additionally, eggs of Ascaris sp. and T. trichiura were found in dogs. This would relate to the coprophagic behaviour of pets and the lack of environmental sanitation (e.g. septic tank, latrines, open-air pits, flooding) in agreement with that observed by Gamboa et al. (2009).

The results obtained as regards the child population showed that $67.8 \%$ was infected by some parasitic species and the majority was infected with pathogenic species. Several studies showed similar values in children of other countries (Abreu dos Santos, Gurgel-Gonçalves, \& Rodrigues Machado, 2014; Cañete, Díaz, Avalos García, Laúd Martinez, \& Manuel Ponce, 2012; Devera et al., 2014). In Argentina, the frequency of parasitosis corresponds with the country's complex mosaic of climatic and socioeconomic variability and shows a declining trend from north to south and from east to west (Navone et al., 2017; Socías et al., 2014). Different studies have reported dissimilar results when comparing parasitism with regard to the sex and age of the individuals (Devera et al., 2014; Lacoste Laugart et al., 2012). In this study, boys were more infected than girls (54.6\% versus $45.4 \%$ ), as well as 6 -year-old children and older, who were significantly more parasitized than younger children (65.0\% versus 35.0\%). In addition, regarding their hygiene habits, it was observed that those who did not wash their hands after caressing their pets had a higher risk for parasitic infection. This could relate to the fact that schoolchildren maintain close contact with the sources of parasitic infection through play and insufficient hygiene habits (Dado et al., 2012; Solano, Acuña, Barón, Morón de Salim, \& Sánchez, 2008).

Specific richness was 11 , and the most prevalent species were Blastocystis sp., E. vermicularis and G. lamblia, according to other studies in different localities (Cañete et al., 2012; Garraza, Zonta, Oyhenart, \& Navone, 2014; Juárez \& Rajal, 2013; Socías et al., 2014).

The transmission of protozoa by unsafe food and water consumption or by the use of objects contaminated with faeces is mainly favoured by inadequate hygiene practices (e.g. no hand washing) and by the lack of sanitary services (i.e. sewage system, piped water system) (Belleza et al., 2015; Pereira, Rodrigues, Bahia-De-Oliveira, Coelho, \& Barata, 2016; Thompson, 2000). Likewise, the presence of E. coli has been significantly associated to flooding, a risk factor that would make the pre-existing socio-environmental conditions of the population worse, thus increasing the risk for parasitic infection via faecal contamination.

Furthermore, E. vermicularis was greater in children with onychophagia and in 6 year olds and older whose parents completed only primary studies, these therefore being factors of greater infection risk. These results are not surprising when considering the transmission by 


\begin{tabular}{|c|c|c|c|c|}
\hline \multirow[b]{2}{*}{ Variables } & \multirow[b]{2}{*}{ Parasitosis } & \multicolumn{3}{|c|}{ Parasitic species $^{b}$} \\
\hline & & Blastocystis sp. & $\begin{array}{l}\text { Enterobius } \\
\text { vermicularis }\end{array}$ & Entamoeba coli \\
\hline Age group & $\chi^{2}=3.7 ; p<.05$ & & $\chi^{2}=9.1 ; p<.01$ & \\
\hline Flooding & & & & $p=.03$ \\
\hline Mother's education & & $p=.03$ & & $p=.03$ \\
\hline Father's education & & $p=.02$ & $p=.04$ & \\
\hline $\begin{array}{l}\text { Handwashing after } \\
\text { playing with pets }\end{array}$ & $\chi^{2}=7.3 ; p<.01$ & & & \\
\hline Onychophagia & & & $\chi^{2}=4.1 ; p<.05$ & \\
\hline
\end{tabular}

${ }^{a}$ Chi-square test $\left(\chi^{2}\right)$ and Fisher's exact test were used to evaluate independence of variables.

${ }^{b}$ The other parasitic species were evaluated, but only those with significant association with the variables were shown.
TABLE 5 Variables selected by statistically significant association ${ }^{\mathrm{a}}$
TAB LE 6 Variables included in the final logistic regression models $^{\mathrm{a}}$

\begin{tabular}{|c|c|c|c|c|}
\hline \multirow[b]{2}{*}{ Variables } & \multicolumn{4}{|c|}{ Model coefficients } \\
\hline & $\beta$ & SE & OR $(95 \% \mathrm{Cl})$ & $p$-value \\
\hline \multicolumn{5}{|l|}{ Parasitosis $^{\mathrm{b}}$} \\
\hline $\begin{array}{l}\text { 6-year-old children } \\
\text { and older }\end{array}$ & 0.6 & 0.35 & $1.9(1.0-3.7)$ & 0.07 \\
\hline $\begin{array}{l}\text { No handwashing after } \\
\text { playing with pets }\end{array}$ & 1.0 & 0.35 & $2.8(1.4-5.5)$ & 0.003 \\
\hline \multicolumn{5}{|l|}{ Blastocystis sp. $^{\mathrm{c}}$} \\
\hline $\begin{array}{l}\text { Basic level of father's } \\
\text { education }\end{array}$ & 1.2 & 0.5 & $3.4(1.3-8.7)$ & 0.01 \\
\hline \multicolumn{5}{|l|}{ Enterobius vermicularis ${ }^{\mathrm{d}}$} \\
\hline $\begin{array}{l}\text { 6-year-old children } \\
\text { and older and basic } \\
\text { level of father's } \\
\text { education }\end{array}$ & 1.3 & 0.5 & $3.6(1.4-9.1)$ & 0.007 \\
\hline Onychophagia & 0.5 & 0.4 & $1.6(0.7-3.7)$ & 0.3 \\
\hline \multicolumn{5}{|l|}{ Entamoeba colie } \\
\hline $\begin{array}{l}\text { Basic level of mother's } \\
\text { education }\end{array}$ & 1.3 & 0.8 & $3.6(0.8-15.9)$ & 0.09 \\
\hline Flooding & 1.5 & 0.8 & $4.4(0.9-16.6)$ & 0.05 \\
\hline
\end{tabular}

$\mathrm{SE}$, standard error; OR, odds ratio; $\mathrm{Cl}$, confidence interval; $\mathrm{RD}$, residual deviance; AIC, Akaike Information Criterion.

${ }^{a}$ Other models were checked, but only the selected models were shown.

${ }^{\text {b}}$ Selected model: Age group + Handwashing after playing with pets. $\mathrm{RD}=0.2 ; \mathrm{AIC}=21.9 ; p=.7$.

${ }^{\mathrm{c}}$ Selected model: Father's education. $\mathrm{RD}=1.2 ; \mathrm{AIC}=19.4 ; p=.5$.

${ }^{\mathrm{d}}$ Selected model: Age group*Father's education + Onychophagia. RD = 0.9; $\mathrm{AIC}=30.6 ; p=.8$.

${ }^{\text {e}}$ Selected model: Mother's education + Flooding. $\mathrm{RD}=0.5 ; \quad \mathrm{AIC}=16.2$; $p=.5$.

anus-hand-mouth route that favours the scattering of eggs over various surfaces (included the body and hair of pets) and it is worsened by overcrowding and by sharing beds and clothes (Cazorla, Acosta, Zarraga, \& Morales, 2006; Chai et al., 2015; Zonta, Susevich, Gamboa, $\&$ Navone, 2016). Likewise, the education level of the parents has turned out to be an infection risk factor for Blastocystis sp. and E. coli. According to other studies (Garraza et al., 2014; Zonta et al., 2013), the lack of information about the biology of intestinal parasites, their means of transmission and the strategies to prevent these parasitoses would increase the risk of infection in children. This suggests the need to continue with the activities of divulgation, surveillance and control of intestinal parasitoses in the child population from within the family and the educational and governmental institutions.

Three species of geohelminths (i.e. A. lumbricoides, T. trichiura and S. stercoralis) with prevalence values between 1.4 and $4.7 \%$ were identified. These infections constitute a major health problem mainly for impoverished populations, that is for residents of rural distant areas and in periurban neighbourhoods that have poor access to health services (Navone, Gamboa, Oyhenart, \& Orden, 2006; Zonta, Oyhenart, \& Navone, 2010). Geohelminthiases are included among the neglected infectious diseases (NIDs) because they get diminished attention in public health priority (WHO, 2016). Thus, these infections are an indicator of the deficiencies in the sanitary and ecological conditions of their hosts and are benefited by the cultural practices of the population such as defecating openly, walking barefoot and being in close contact with soil (Socías et al., 2014). These practices have been observed in many of the children participating in this study.

The results obtained show the existence of a worrying epidemiological scenario that stresses the importance of zoonotic parasitosis as a serious public health problem, and also of the socio-environmental conditions and hygiene practices of the studied population. The close contact of children with their pets, the insufficient hygiene habits, the inadequate disposition of canine faeces, the lack of environmental sanitation and of information about the parasitic infections, is the most relevant factors observed in this population.

Other findings that would have been of interest include the application of other diagnostic techniques in children (e.g. ELISA, Western Blot) to increase the parasitological knowledge of the region. Despite this limitation, the results of this study reveal the need to engage in more in-depth activities of prevention, surveillance and control of these infections as of the commitment of the scientific community in agreement with regional and national programmes 
of education, public health and responsible pet ownership. Letra Mateus et al. (2014) emphasize the importance of epidemiological studies with a multidisciplinary approach to address this problem. The One Health concept invites the health community and environmentally related disciplines to unify their efforts to combat zoonotic parasites (e.g., T. canis, A. caninum). Several studies show that the One Health approach offers valuable information to generate a global synergism for all aspects of health care for humans, animals and the environment (Ryan, Zahedi, \& Paparini, 2016; Schurer, Ndao, Quewezance, Elmore, \& Jenkins, 2014). Indeed, the integration of different disciplines is fundamental for the development of research programmes that will allow to take decisions to mitigate the effect of intestinal parasitosis.

\section{ACKNOWLEDGEMENTS}

The authors are grateful to the local authorities, the education community and the people living in the surveyed neighbourhoods for their active cooperation. We are also thankful to Graciela Minardi for her help with the statistical analyses and to Pilar Martínez for the translation of the manuscript. This work was funded by national projects (UNLP N759, PIP CONICET N734 and PIO CONICET-UNLP N13420130100004CO).

\section{CONFLICT OF INTEREST}

The authors declare that they have no conflicts of interest.

\section{ORCID}

P. Cociancic iD http://orcid.org/0000-0003-0599-6081

\section{REFERENCES}

Abreu dos Santos, A., Gurgel-Gonçalves, R., \& Rodrigues Machado, E. (2014). Factors associated with the occurrence of intestinal parasites in children living in the Federal District of Brazil. Revista de Patología Tropical, 43, 89-97. https://doi.org/10.5216/rpt.v43i1.29374

Amissah-Reynolds, P. K., Monney, I., Adowah, L. M., \& Agyemang, S. O. (2016). Prevalence of helminths in dogs and owners'awareness of zoonotic diseases in Mampong, Ashanti, Ghana. Journal of Parasitology Research, 2016, 1-6. https://doi.org/10.1155/2016/1715924

Becerril Flores, M. A., \& Romero Cabello, R. (2004). Parasitología médica: De las moléculas a la enfermedad. México: Mc Graw Hill Interamericana.

Belleza, M. L. B., Cadacio, J. L. C., Borja, M. P., Solon, J. A. A., Padilla, M. A., Tongol-Rivera, P. N., \& Rivera, W. L. (2015). Epidemiologic study of Blastocystis Infection in an urban community in the Philippines. Journal of Environmental and Public Health, 2015, 1-7. https://doi. org/10.1155/2015/894297

Bowman, D. D., Montgomery, S. P., Zajac, A. M., Eberhard, M. L., \& Kazacos, K. R. (2010). Hookworms of dogs and cats as agents of cutaneous larva migrans. Trends in Parasitology, 26, 162-167. https://doi.org/10.1016/j. pt.2010.01.005

Bwalya, E. C., Nalubamba, K. S., Hankanga, C., \& Namangala, B. (2011). Prevalence of canine gastrointestinal helminths in urban Lusaka and rural Katete Districts of Zambia. Preventive Veterinary Medicine, 100, 252-255. https://doi.org/10.1016/j.prevetmed.2011.04.015
Cañete, R., Díaz, M. M., Avalos García, R., Laúd Martinez, P. M., \& Manuel Ponce, F. (2012). Intestinal parasites in children from a Day Care Centre in Matanzas City, Cuba. PLoS ONE, 7, e51394. https://doi.org/10.1371/ journal.pone.0051394

Cazorla, D. J., Acosta, M. E., Zarraga, A., \& Morales, P. (2006). Estudio clínico-epidemiológico de enterobiasis en preescolares y escolares de Taratara, Estado Falcón, Venezuela. Parasitología latinoamericana, 61, 43-53.

Chai, J. Y., Yang, S. K., Kim, J. W., Choi, S. L., Song, G. Y., Jung, B. K., ... Tin, H. H. (2015). High prevalence of Enterobius vermicularis infection among schoolchildren in three townships around Yangon, Myanmar. The Korean Journal of Parasitology, 53, 771. https://doi.org/10.3347/ kjp.2015.53.6.771

Dado, D., Izquierdo, F., Vera, O., Montoya, A., Mateo, M., Fenoy, S., ... Miro, G. (2012). Detection of zoonotic intestinal parasites in public parks of Spain. Potential epidemiological role of Microsporidia. Zoonoses and Public Health, 59, 23-28. https://doi. org/10.1111/j.1863-2378.2011.01411.x

Dantas-Torres, F., \& Otranto, D. (2014). Dogs, cats, parasites, and humans in Brazil: Opening the black box. Parasites \& Vectors, 7, 22. https://doi. org/10.1186/1756-3305-7-22

Devera, R., Blanco, Y., Amaya, I., Nastasi, M. J., Rojas, G., \& Vargas, B. (2014). Parásitos intestinales en habitantes de la comunidad rural "La Canoa", Estado Anzoátegui, Venezuela. Revista Venezolana de Salud Pública, 2, 15-22.

Dopchiz, M. C., Lavallén, C. M., Bongiovanni, R., Gonzalez, P. V., Elissondo, C., Yannarella, F., \& Denegri, G. (2013). Endoparasitic infections in dogs from rural areas in the Lobos District, Buenos Aires province, Argentina. Revista Brasileira de Parasitologia Veterinária, 22, 92-97.

Dunn, J. J., Columbus, S. T., Aldeen, W. E., Davis, M., \& Carroll, K. C. (2002). Trichuris vulpis recovered from a patient with chronic diarrhea and five dogs. Journal of Clinical Microbiology, 40, 2703-2704. https://doi. org/10.1128/JCM.40.7.2703-2704.2002

Feldmeier, H., \& Schuster, A. (2012). Mini review: Hookworm-related cutaneous larva migrans. European Journal of Clinical Microbiology \& Infectious Diseases, 31, 915-918. https://doi.org/10.1007/s10096-011-1404-x

Fontanarrosa, M. F., Vezzani, D., Basabe, J., \& Eiras, D. F. (2006). An epidemiological study of gastrointestinal parasites of dogs from Southern Greater Buenos Aires (Argentina): Age, gender, breed, mixed infections, and seasonal and spatial patterns. Veterinary Parasitology, 136, 283295. https://doi.org/10.1016/j.vetpar.2005.11.012

Gamboa, M. I., Giambelluca, L. A., \& Navone, G. T. (2014). Distribución espacial de las parasitosis intestinales en la ciudad de La Plata, Argentina. Medicina (Buenos Aires), 74, 363-370.

Gamboa, M. I., Kozubsky, L. E., Costas, M. E., Garraza, M., Cardozo, M. I., Susevich, M. L., ... Navone, G. T. (2009). Asociación entre geohelmintos y condiciones socioambientales en diferentes poblaciones humanas de Argentina. Revista Panamericana de Salud Pública, 26(1), 1-8.

Garraza, M., Zonta, M. L., Oyhenart, E. E., \& Navone, G. T. (2014). Estado nutricional, composición corporal y enteroparasitosis en escolares del departamento de San Rafael, Mendoza, Argentina. Nutrición Clínica y Dietética Hospitalaria, 34, 31-40. https://doi.org/10.12873/341garraza

Hurtado, M. A., Giménez, J. E., \& Cabral, M. A. (2006). Análisis ambiental del partido de La Plata: aportes al ordenamiento territorial. Buenos Aires: Consejo Federal de Inversiones.

Instituto Nacional de Estadística y Censos (INDEC) (2010). Censo Nacional de población, hogares y vivienda. Buenos Aires, Argentina: Ministerio de Economía de la Nación. Retrieved from http://www.indec.gov.ar

Juárez, M. M., \& Rajal, V. B. (2013). Parasitosis intestinales en Argentina: Principales agentes causales encontrados en la población y en el ambiente. Revista Argentina de Microbiología, 45, 191-204.

La Sala, L. F., Leiboff, A., Burgos, J. M., \& Costamagna, S. R. (2015). Spatial distribution of canine zoonotic enteroparasites in Bahía Blanca, Argentina. Revista Argentina de Microbiología, 47, 17-24. https://doi. org/10.1016/j.ram.2014.12.006 
Lacoste Laugart, E., Rosado García, F. M., Núñez, F. Á., Rodríguez Peña, M. S., Medina Fundora, I. C., \& Suárez Medina, R. (2012). Aspectos epidemiológicos de las parasitosis intestinales en niños de Vegón de Nutrias, Venezuela. Revista Cubana de Higiene y Epidemiología, 50, 330-339.

Lee, A. C., Schantz, P. M., Kazacos, K. R., Montgomery, S. P., \& Bowman, D. D. (2010). Epidemiologic and zoonotic aspects of ascarid infections in dogs and cats. Trends in Parasitology, 26, 155-161. https://doi. org/10.1016/j.pt.2010.01.002

Letra Mateus, T., Castro, A., Ribeiro, J. N., \& Vieira-Pinto, M. (2014). Multiple zoonotic parasites identified in dog feces collected in Ponte de Lima, Portugal-A potential threat to human health. International Journal of Environmental Research and Public Health, 11, 9050-9067. https://doi. org/10.3390/ijerph110909050

Mehlhorn, H., Düwel, D., \& Raether, W. (1992). Atlas de Parasitología Veterinaria. Barcelona: Grass Ediciones.

Navone, G. T., Gamboa, M. I., Oyhenart, E. E., \& Orden, A. B. (2006). Parasitosis intestinales en poblaciones Mbyá-Guaraní de la Provincia de Misiones, Argentina: Aspectos epidemiológicos y nutricionales. Cadernos de Saúde Pública, 22, 1089-1100. https://doi.org/10.1590/ S0102-311X2006000500022

Navone, G. T., Zonta, M. L., Cociancic, P., Garraza, M., Gamboa, M. I., Giambelluca, L. A., ... Oyhenart, E. E. (2017). Estudio transversal de las parasitosis intestinales en poblaciones infantiles de Argentina. Rev Panam Salud Pública, 41, e24.

Overgaauw, P. A., \& van Knapen, F. (2013). Veterinary and public health aspects of Toxocara spp. Veterinary Parasitology, 193, 398-403. https:// doi.org/10.1016/j.vetpar.2012.12.035

Oyhenart, E. E., Garraza, M., Bergel, M. L., Torres, M. F., Castro, L. E., Luis, M. A., ... Navone, G. T. (2013). Caracterización del estado nutricional, enteroparasitosis y condiciones socio-ambientales de la población infanto-juvenil del partido de La Plata/Characterization of nutritional status, enteroparasitosis and socio-environmental conditions of the infant-juvenile population from La Plata department. Revista Argentina de Antropología Biológica, 15, 47-60. https://doi.org/10.17139/ raab.2013.0015.1

Pereira, E. B. S., Rodrigues, S. L. C., Bahia-De-Oliveira, G. H., Coelho, S. V. B., \& Barata, R. A. (2016). Detection of intestinal parasites in the environments of a public school in the town of Diamantina, Minas Gerais State, Brazil. Revista do Instituto de Medicina Tropical de São Paulo, 58 , 51-54. https://doi.org/10.1590/S1678-9946201658051

R Core Team (2015). R: A language and environment for statistical computing. Vienna, Austria: R Foundation for Statistical Computing. Retrieved from http://www.R-project.org/

Ryan, U., Zahedi, A., \& Paparini, A. (2016). Cryptosporidium in humans and animals-a one health approach to prophylaxis. Parasite Immunology, 38, 535-547. https://doi.org/10.1111/pim.12350

Schurer, J. M., Ndao, M., Quewezance, H., Elmore, S. A., \& Jenkins, E. J. (2014). People, pets, and parasites: One Health surveillance in Southeastern Saskatchewan. The American Journal of Tropical Medicine and Hygiene, 90, 1184-1190. https://doi.org/10.4269/ajtmh.13-0749

Semenas, L., Flores, V., Viozzi, G., Vázquez, G., Pérez, A., \& Ritossa, L. (2014). Helmintos zoonóticos en heces caninas de barrios de Bariloche (Río Negro, Patagonia, Argentina). Revista Argentina de Parasitología, 2, 22-27.

Socías, M. E., Fernández, A., Gil, J. F., \& Krolewiecki, A. J. (2014). Geohelmintiasis en la Argentina: Una revision sistematica. Medicina (Buenos Aires), 74, 29-36.

Solano, L., Acuña, I., Barón, M. A., Morón de Salim, A., \& Sánchez, A. (2008). Influencia de las parasitosis intestinales y otros antecedentes infecciosos sobre el estado nutricional antropométrico de niños en situación de pobreza. Parasitología Latinoamericana, 63, 12-19.

Soriano, S. V., Pierangeli, N. B., Roccia, I., Bergagna, H. F. J., Lazzarini, L. E., Celescinco, A., ... Basualdo, J. A. (2010). A wide diversity of zoonotic intestinal parasites infects urban and rural dogs in Neuquén, Patagonia, Argentina. Veterinary Parasitology, 167, 81-85. https://doi. org/10.1016/j.vetpar.2009.09.048

Thienpont, D., Rochette, F., \& Vanparijs, O. F.J. (1979). Diagnóstico de las helmintiasis por medio del examen coprológico. Buenos Aires, Argentina: Johnson \& Johnson de Argentina S.A. Comercial e Industrial. Div Veterinaria.

Thompson, R. A. (2000). Giardiasis as a re-emerging infectious disease and its zoonotic potential. International Journal for Parasitology, 30, 12591267. https://doi.org/10.1016/S0020-7519(00)00127-2

Traversa, D. (2012). Pet roundworms and hookworms: A continuing need for global worming. Parasites \& Vectors, 5, 91. https://doi. org/10.1186/1756-3305-5-91

Traversa, D., Di Cesare, A., Lia, R. P., Castagna, G., Meloni, S., Heine, J., ... Schaper, R. (2011). New insights into morphological and biological features of Capillaria aerophila (Trichocephalida, Trichuridae). Parasitology Research, 109, 97-104. https://doi.org/10.1007/s00436-011-2406-4

Traversa, D., di Regalbono, A. F., Di Cesare, A., La Torre, F., Drake, J., \& Pietrobelli, M. (2014). Environmental contamination by canine geohelminths. Parasites \& Vectors, 7, 67. https://doi. org/10.1186/1756-3305-7-67

World Health Organization (1991). Basic laboratory methods in medical parasitology. Geneva: WHO.

World Health Organization (1994). Medios Auxiliares para el diagnóstico de las parasitosis intestinales, 9 láminas. Ginebra: WHO.

World Health Organization (2016). Geohelmintiasis. Retrieved from http:// www.paho.org/hq/index.php?option=com_content\&view=article \&id $=5747$ \&ltemid $=4138$

Zanzani, S. A., Gazzonis, A. L., Scarpa, P., Berrilli, F., \& Manfredi, M. T. (2014). Intestinal parasites of owned dogs and cats from metropolitan and micropolitan areas: Prevalence, zoonotic risks, and pet owner awareness in northern Italy. BioMed Research International, 2014, 1-10. https://doi. org/10.1155/2014/696508

Zonta, M. L., Bergel, M. L., Cociancic, P., Gamboa, M. I., Garraza, M., Cesani, M. F., ... Navone, G. T. (2013). Enteroparasitosis en niños de Villaguay, Entre Ríos: Un estudio integrado al estado nutricional y al ambiente. Revista Argentina de Parasitología, 1, 86-109.

Zonta, M. L., Oyhenart, E. E., \& Navone, G. T. (2010). Nutritional status, body composition, and intestinal parasitism among the Mbyá-Guaraní communities of Misiones, Argentina. American Journal of Human Biology, 22, 193-200. https://doi.org/10.1002/ajhb.20977

Zonta, M. L., Susevich, M. L., Gamboa, M. I., \& Navone, G. T. (2016). Parasitosis intestinales y factores socioambientales: Estudio preliminar en una población de horticultores. Salud(i)Ciencia, 21, 814-823.

How to cite this article: Cociancic P, Zonta ML, Navone GT. A cross-sectional study of intestinal parasitoses in dogs and children of the periurban area of La Plata (Buenos Aires, Argentina): Zoonotic importance and implications in public health. Zoonoses Public Health. 2017;00:1-10.

https://doi.org/10.1111/zph.12408 